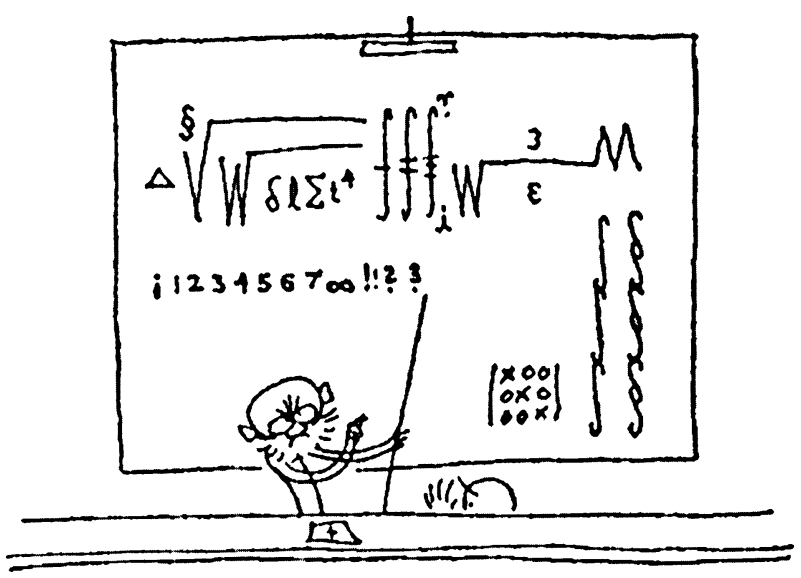

\title{
WIDE ROAD
}

To make a name for learning when other roads are barred, take something very easy and make it very hard.

\section{Piet Hein}

Copyright ( $)$ Piet Hein Illustration \& Grook

Reprinted with kind permission from Piet Hein a/s, Middelfart, Denmark 